\title{
FISIOLOGIA DO EXERCÍCIO EM EQUINOS
}

SECANI, Aline ${ }^{1}$
LÉGA, Elzylene $^{2}$

Recebido em: 2009-08-04

Aprovado em: $2009-10-10$

ISSUE DOI: $10.3738 / 1982.2278 .282$

RESUMO: A fisiologia do exercício estuda as respostas fisiológicas e bioquímicas do cavalo durante e após o exercício físico. Para que se inicie o exercício e ocorra a contração muscular são necessários combustíveis para a produção de adenosina trifosfato (ATP), sendo indispensável a manutenção deste para reorganização do ciclo, ocorrendo através de processos metabólicos que variam conforme a intensidade e a duração do exercício, podendo ocorrer a síntese de ATP pela via anaeróbica por um substrato imediato como a creatina fosfato $(\mathrm{CP})$ ou pela glicose através da glicólise, ou ainda, ocorre pela via aeróbica através também da glicose envolvendo o ciclo de Krebs, porém alguns destes mecanismos produzem metabólitos que podem resultar na queda da performance. Durante esses processos também ocorrem alterações fisiológicas na tentativa de restabelecer os parâmetros do animal. Sendo assim, este trabalho teve o intuito de realizar uma revisão de todas estas alterações, bem como descrever as necessidades fisiológicas para a realização dos exercícios na espécie equina.

Palavras-chave: Equino. Fisiologia. Exercício.

SUMMARY: The exercise physiology studies the physiological and biochemical responses of the horse during and after exercise. In order to start the exercise and to occur the muscle contraction it's necessary fuel for the production of adenosine triphosphate (ATP), and it's essential the maintenance of this fuels for reorganization of the cycle, occurring through metabolic processes that vary depending on the intensity and duration of exercise, possible to occur the synthesis of ATP through anaerobic respiration through an immediate substrate such as creatine phosphate $(\mathrm{CP})$ or the glucose through glycolysis, or, occurs with aerobic respiration through the glucose involving the Kreb's Citric Acid Cycle, although those mechanisms produce metabolites that may result in a performance decrease. During these processes also occur physiological changes in an attempt to restore the animal parameters. Thus, this work had the intention of reviewing all these changes, and describes the physiological needs for the conduction of the exercises in equine species.

Key words: Equine. Physiology. Exercise

\section{INTRODUÇÃO}

Os equinos têm grande importância no desenvolvimento do Brasil, o qual pode ser observado desde o Brasil colônia, quando o cavalo passou por todos os ciclos extrativistas, agrícolas e de mineração. $\mathrm{Na}$ atualidade, este animal é usado para o trabalho rural e atividades de esporte e lazer (GUERRA; MEDEIROS, 2006). Atualmente o Brasil possui o terceiro maior rebanho de equinos do mundo com 5,9

\footnotetext{
${ }^{1}$ Médica Veterinária, alinesecani@terra.com.br

${ }^{2}$ Médica Veterinária, Dra. e Profa. do Centro Universitário Moura Lacerda, lenelega@hotmail.com
} 
milhões de animais, sendo superado pela China com 7,9 milhões e pelo México com 6,3 milhões de cabeças. Cinco milhões de animais são utilizados para lida nas propriedades rurais, principalmente do gado bovino e os outros 900 mil cavalos, possuindo maior valor agregado, são representados por 23 associações de criadores de diferentes raças. $\mathrm{O}$ mercado de equinos movimenta cerca de $\mathrm{R} \$ 7,5$ bilhões ao ano, gerando 3,2 milhões de empregos diretos e indiretos (GUERRA; MEDEIROS, 2006). A fisiologia do exercício refere-se aos estudos da resposta do cavalo ao exercício. Estudos da fisiologia do exercício envolvem mensurações de temperatura corporal, batimento cardíaco, concentração de ácido lático e oxigênio, sendo que a bioquímica do exercício referem-se a estudos relacionados à forma com que as células do corpo e os componentes celulares respondem durante o exercício, por exemplo, como ocorre o suprimento de energia e quais combustíveis são usados durante diversos tipos de exercícios (EVANS, 2000). A utilização sustentável dos animais faz com que ocorra a busca por novas tecnologias e execução de pesquisas, prevenindo assim o excesso de treinamento (Overtraining) que acarretam lesões, principalmente músculo-esquelético (GRAMKOW; FERRAZ, 2007). Desse modo, a fisiologia do exercício torna-se ferramenta fundamental no monitoramento da intensidade do treinamento e na avaliação de atletas da espécie equina (GRAMKOW; FERRAZ, 2007).

\section{Desenvolvimento}

Um aumento da atividade muscular ocorre quando o cavalo inicia uma atividade física (SILVA, 2005). O metabolismo no músculo esquelético é especializado em produzir adenosina trifosfato (ATP) como fonte imediata de energia (LEHNINGER et $a l$, 2000). Para que ocorra a contração, os músculos precisam de energia. No início, essa energia é fornecida pela metabolização de combustíveis estocados no interior das células musculares. Quando cessados estes estoques de energia, o combustível passa a ser fornecido por outras áreas do corpo, como o fígado, onde são trazidos às miofibrilas pela corrente sanguínea sob a forma de glicose e de ácidos graxos livres (SILVA, 2005). Dependendo do grau de atividade muscular os músculos irão utilizar ácidos graxos, corpos cetônicos e glicose como combustível, sendo que em repouso os combustíveis utilizados são ácidos graxos do tecido adiposo e corpos cetônicos do fígado, estes são oxidados e degradados a acetilcoenzima A, que entra no ciclo de Krebs para oxidação 
até dióxido de carbono (CO2), fornecendo ATP pela fosforilação oxidativa (LEHNINGER et al, 2000).

O oxigênio é fornecido pelo pulmão através das hemácias, que associada à hemoglobina é capaz de transportá-lo. O CO2, um catabólito (resíduo metabólico) é resultante deste mecanismo, e deve ser removido das células para os músculos trabalharem perfeitamente. $\mathrm{O} \mathrm{CO}_{2}$ então se liga à hemoglobina onde é removido através da corrente sanguínea e eliminado pelos pulmões (SILVA, 2005).

A energia é necessária para bombear íons e moléculas orgânicas e manter gradientes iônicos necessários para gerar potenciais de ação e condutividade elétrica no sistema nervoso (HODGSON; ROSE, 1994). A energia presente nos alimentos fica disponível para os animais sob a forma de adenosina trifosfato (ATP) (BALDISSERA, 1997). Quando o animal está em repouso, assim como no exercício, os substratos energéticos disponíveis são carboidratos e lipídios. A contribuição de cada nutriente durante o exercício é determinada pela intensidade e pela duração do esforço (GRAMKOW; FERRAZ, 2007). O equino tem grande capacidade de realizar trabalhos, sua capacidade aeróbica e anaeróbica também são altas e relatadas duas vezes maiores que nos seres humanos (HODGSON; ROSE, 1994), uma vez que os cavalos apresentam maior peso médio e maior velocidade de corrida (BALDISSERA, 1997). Os cavalos de corrida de 400 metros podem atingir velocidades de $70 \mathrm{~km} / \mathrm{h}$, os cães atingem até 60 $\mathrm{km} / \mathrm{h}$ em corridas de 500 metros, e humanos aproximadamente $36 \mathrm{~km} / \mathrm{h}$ sendo que em corridas de $100 \mathrm{~km}$ atinge cerca de $16 \mathrm{~km} / \mathrm{h}$ e $1000 \mathrm{~km}$ atinge velocidades de 6 a 8 $\mathrm{km} / \mathrm{h}$. Os camelos em distancias de 4 a $10 \mathrm{~km}$ podem atingir até $36 \mathrm{~km} / \mathrm{h}$, ou seja as velocidades máximas nessas espécies variam sendo $19 \mathrm{~m} / \mathrm{s}$ em cavalos, $16,6 \mathrm{~m} / \mathrm{s} \mathrm{em}$ cães e 10 a 11 m/s em humanos e camelos atletas (Figura 1) (HODGSON; ROSE, 1994).

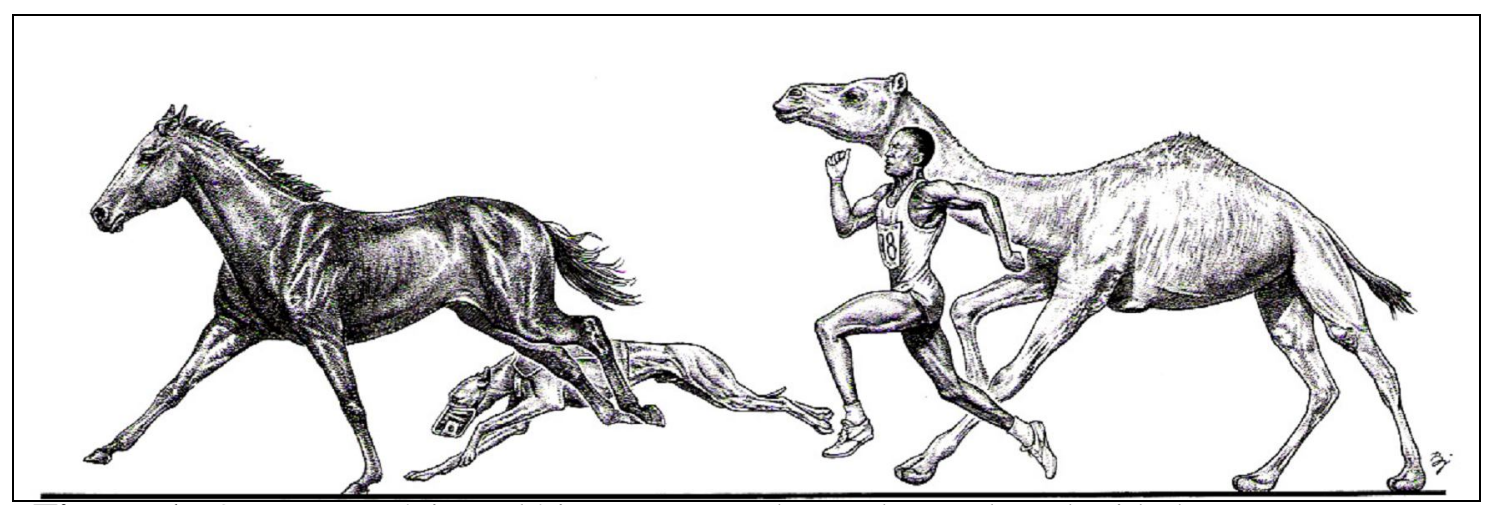

Figura 1: Quatro espécies atléticas mostrando a relação de velocidade.

Fonte: (HODGSON; ROSE, 1994). 
Os exercícios físicos são dependentes da oferta de adenosinatrifosfato (ATP) (EVANS, 2000), que quando hidrolisado pela ação da enzima ATPase, forma a adenosina difosfato (ADP) e fosfato inorgânico (PI). ADP e Pi se unem por uma ligação de alta energia. Essa ligação é rompida pela ATPase ocorrendo a liberação de energia que será utilizada para a realização de exercícios como a contração muscular (GRAMKOW; FERRAZ, 2007). Quando os músculos se contraem há uma união de actina e miosina para formar as pontes; os filamentos de miosina possuem em sua cabeça uma molécula de ATP que durante a contração é hidrolisada e libera energia (HODGSON; ROSE, 1994). Essa reação bioquímica pode ser representada pela equação:

$$
\mathrm{ATP}+\mathrm{H} 2 \mathrm{O} \longrightarrow \mathrm{ATPase} \quad \mathrm{ADP}+\mathrm{Pi}+\mathrm{H}++ \text { Energia }
$$

(HODGSON; ROSE, 1994; GRAMKOW; FERRAZ, 2007). A energia liberada é utilizada para a manutenção da temperatura corporal, distribuição normal dos íons sódio e potássio no corpo, além de ter importância na contração e relaxamento das células musculares de exercício (HODGSON; ROSE, 1994).

No trato gastrointestinal, nutrientes como a glicose, são absorvidos pelo organismo. A glicose é transportada pelo sistema circulatório até o fígado, sendo convertida em glicogênio. No fígado é armazenada ou vai para o músculo sendo metabolizada em energia ou armazenada como glicogênio para ser usado futuramente. No músculo, o glicogênio é metabolizado a piruvato pela via glicolítica. Na via aeróbica o piruvato é metabolizado via ciclo do ácido tricarboxílico, formando posteriormente dióxido de carbono e água. Por via anaeróbica o piruvato é convertido a ácido lático. $\mathrm{O}$ ácido lático, o dióxido de carbono e a água são removidos do músculo através da corrente sanguínea. O dióxido de carbono é expelido através dos pulmões, a água através dos rins e o ácido lático é ressintetizado a glicose no fígado (GUIMARÃES; ADELL, 1995). Para que os cavalos permaneçam por mais que alguns segundos no exercício devem ser capazes de ressintetizar o ATP. Existem vários caminhos para a ressíntese de ATP e estes são determinados pela intensidade e duração do exercício físico (EVANS, 2000).

Os músculos esqueléticos contêm consideráveis quantidades de fosfocreatina (LEHNINGER et al, 2000), que levam ao caminho mais simples e rápido (7 a 10 segundos) para a produção de ATP pela doação de um grupo fosfato para o ADP, formando ATP, pela reação da creatina quinase (LEHNINGER et al, 2000; 
GRAMKOW; FERRAZ, 2007). É um processo sem gasto de oxigênio e sem formação de ácido lático, sendo denominado de potência anaeróbica aláctica (BALDISSERA, 1997). O fosfato de creatina proporciona uma fonte de energia instantaneamente disponível para esforços de alta intensidade (MORGADO; GALZERANO, 2006) atuando como um substrato imediato para a síntese de ATP (HODGSON; ROSE, 1994). Esta via metabólica está representada na equação a seguir: $(\mathrm{PCR}+\mathrm{ADP}$ Creatina cinase $(\mathrm{CK})$ ATP $+\mathrm{Cr})$. Esta reação é catalisada pela enzima creatina quinase (HODGSON; ROSE, 1994; GRAMKOW; FERRAZ, 2007).

A combinação do ATP com a creatina fosfato é denominado sistema ATP-CP ou "sistema fosfagênico", e este é capaz de fornecer energia para a contração muscular no início do exercício (GRAMKOW; FERRAZ, 2007). Esta via metabólica é importante para provas de curta duração como Corrida de 400 metros, Baliza e Tambor, por fornecer grande quantidade de energia por unidade de tempo (GRAMKOW; FERRAZ, 2007), durando de 6 a 8 segundos ((MORGADO; GALZERANO, 2006).

Os depósitos de CP durante exercícios intensos podem sofrer redução de até 70\%. Estes são recuperados com o animal em repouso ou durante exercícios de baixa intensidade, tendo reutilização pela fibra muscular (GRAMKOW; FERRAZ, 2007).

Cavalos de corrida de 400 metros, durante mais da metade de todo o percurso não respiram, assim não aciona o mecanismo de acoplamento respiração-locomoção (LACERDA, 2004). Nos músculos excessivamente ativos, a demanda de ATP é muito grande e o fluxo sanguíneo não consegue fornecer $\mathrm{O}_{2}$ e combustível em quantidade suficiente para a produção do ATP necessário através de respiração aeróbica (LEHNINGER et al, 2000).

$\mathrm{O}$ fornecimento de energia anaeróbica é mais direto do que a aeróbica e predomina na entrega rápida de energia durante breves períodos de exercício intenso (HODGSON; ROSE, 1994). Em exercícios de alta intensidade e curta duração (mais que 30 segundos), como em provas de salto, apartação e team penning, a principal via para o fornecimento de ATP ocorre pela degradação do glicogênio muscular a lactato (EVANS, 2000; LACERDA, 2004; LEHNINGER et al, 2000) por fermentação com a produção de duas moléculas de ATP por unidade de glicose degradada (LEHNINGER et al, 2000).

O glicogênio é metabolizado a glicose-1-fosfato (G-1-P) por fosforilase, esta é convertida a glicose-6-fosfato G-6-P), que em seguida entra na via glicolítica 
anaeróbica. As reservas de glicogênio em cavalos chegam a $700 \mathrm{mmol}$ de glicose por $\mathrm{kg}$ de músculo, sendo para eles a maior fonte de combustível (HODGSON; ROSE, 1994). A glicose sofre fosforilação a G-6-P no citosol da célula por hexoquinase, nessa reação requer a utilização de uma molécula de ATP, a G-6-P é convertida a frutose-6-fosfato (F-6-P) que é convertida a frutose-1,6-difosfato $\left(\mathrm{F}-1,6-\mathrm{P}_{2}\right)$ com a utilização de outra molécula de ATP. A F-1,6- $\mathrm{P}_{2}$ é metabolizada a duas moléculas de piruvato com a produção de 4 moléculas de ATP e 2 de NADH2, de maneira que o percurso glicolítico anaeróbico rende 3 moléculas de ATP para 1 molécula de glicogênio ou 2 moléculas de ATP para 1 molécula de glicose. No estágio final do percurso anaeróbico ocorre a conversão de piruvato a lactato em uma reação catalisada por lactato desidrogenase que também reoxida o NADH2. Pode ocorrer ainda do piruvato entrar na mitocôndria e participar do ciclo do TCA (HODGSON; ROSE, 1994).

O metabolismo do glicogênio pode ser acompanhado pelo aumento na concentração do lactato, dos íons de hidrogênio e do fosfato inorgânico presente nas células (Glicogênio + 3 ADP $\longrightarrow 2$ lactato + 2 H+ + 3 ATP) (EVANS, 2000).

$\mathrm{Na}$ transição do exercício moderado a intenso, a necessidade do ATP é suprida principalmente pela glicólise e glicogenólise hepático-muscular com intensa atividade da enzima lactato desidrogenase (LDH), ocorrendo acúmulo de lactato e H+ no músculo e no sangue, não pela falta de oxigênio (hipóxia) e sim pelo aumento da intensidade de esforço que promove um desvio da via metabólica para produção de ATP (GRAMKOW; FERRAZ, 2007).

Algumas moléculas de lactato são transportadas para o fígado através da corrente sanguínea e, no fígado, são oxidadas e armazenadas na forma de glicogênio. Durante a realização do exercício ocorre a mobilização dos estoque de glicogênio no fígado o que ajuda a manter as concentrações de glicose no sangue (GRAMKOW; FERRAZ, 2007).

Em exercícios prolongados, isto é, acima de 10 minutos, como no enduro equestre, onde se tem moderada atividade do músculo, o suprimento de energia ocorre pelo metabolismo aeróbico (LEHNINGER et al, 2000; LACERDA, 2004), com utilização da glicose sanguínea além de ácidos graxos e corpos cetônicos (LEHNINGER et al, 2000). Durante exercícios de velocidade baixa as exigências de energia também são baixas, assim o metabolismo aeróbico é capaz de satisfazer condições de ressíntese de ATP (EVANS, 2000), sendo o metabolismo aeróbico a via primária para o ATP ser restabelecido durante exercícios de resistência, como no enduro equestre (GRAMKOW; FERRAZ, 2007). Devido a utilização do oxigênio a velocidade destas reações é bem 
mais lenta que a via anaeróbica, devido à complexidade das reações e a eficiência com que o oxigênio chega até a mitocôndria (MORGADO; GALZERANO, 2006).

A produção aeróbica de ATP ocorre dentro da mitocôndria (HODGSON; ROSE, 1994; BALDISSERA, 1997), envolvendo duas vias metabólicas, o Ciclo de Krebs e a cadeia de transporte de elétrons ( BALDISSERA 1997; GRAMKOW; FERRAZ, 2007 ), a partir da oxidação de gorduras e da glicose, resultando desta produção, dióxido de carbono e água, com a produção de 38 moléculas de ATP ao final da reação (BALDISSERA, 1997; LEHNINGER et al, 2000).

As coenzimas nicotinamida-adenina-dinucleotídeo (NAD) e flavina-adeninadinucleotídeo (FAD) atuam como carreadoras de hidrogênio e são reduzidas a NADH2 e FADH2. As coenzimas são essenciais para a fosforilação aeróbica, mas as suas concentrações dentro do músculo são baixas, devendo ser reoxidadas via transporte de cadeia de elétrons em que o oxigênio atua como aceitador final de hidrogênio para formar água (HODGSON; ROSE, 1994).

A glicose é fosforilada e degradada pela glicólise até piruvato, que é convertido em acetil - CoA e oxidado através do Ciclo de Krebs (LEHNINGER et al, 2000). O piruvato é derivado para o metabolismo anaeróbico de glicose e glicogênio no citoplasma, sendo transportado para dentro da mitocôndria pela atividade da piruvato desidrogenase, que converte piruvato em acetil coenzima A (acetil- CoA) por via aeróbica. A acetil- CoA entra no ciclo do ácido tricarboxílico (TCA) por combinação com o oxaloacetato (OAA). Neste ciclo existem várias desidrogenações e descarboxilações que consomem o grupo acetil do acetil- CoA, permitindo a recuperação do volume inicial de OAA. Além disso, são produzidos no ciclo 2 moléculas de $\mathrm{CO} 2$, transferidos 8 átomos de hidrogênio para formar 3 moléculas de NADH2 e 1 FADH2 e 1 molécula de ATP. A NADH2 e FADH2 são submetidas a fosforilação oxidativa. Cada molécula de $\mathrm{NADH} 2$ combina com $\mathrm{O} 2$ para formar $\mathrm{H} 2 \mathrm{O}$ em uma reação ligada a um percurso que combina 3 moléculas de ADP e 3 moléculas de Pi para formar 3 moléculas de ATP. Com o FADH2 ocorre uma reação similar produzindo 2 moléculas de ATP. O resultado final do ciclo do ácido tricarboxílico é a produção de 12 moléculas de ATP para cada molécula de acetil - CoA (Figura 2) (HODGSON; ROSE, 1994). 


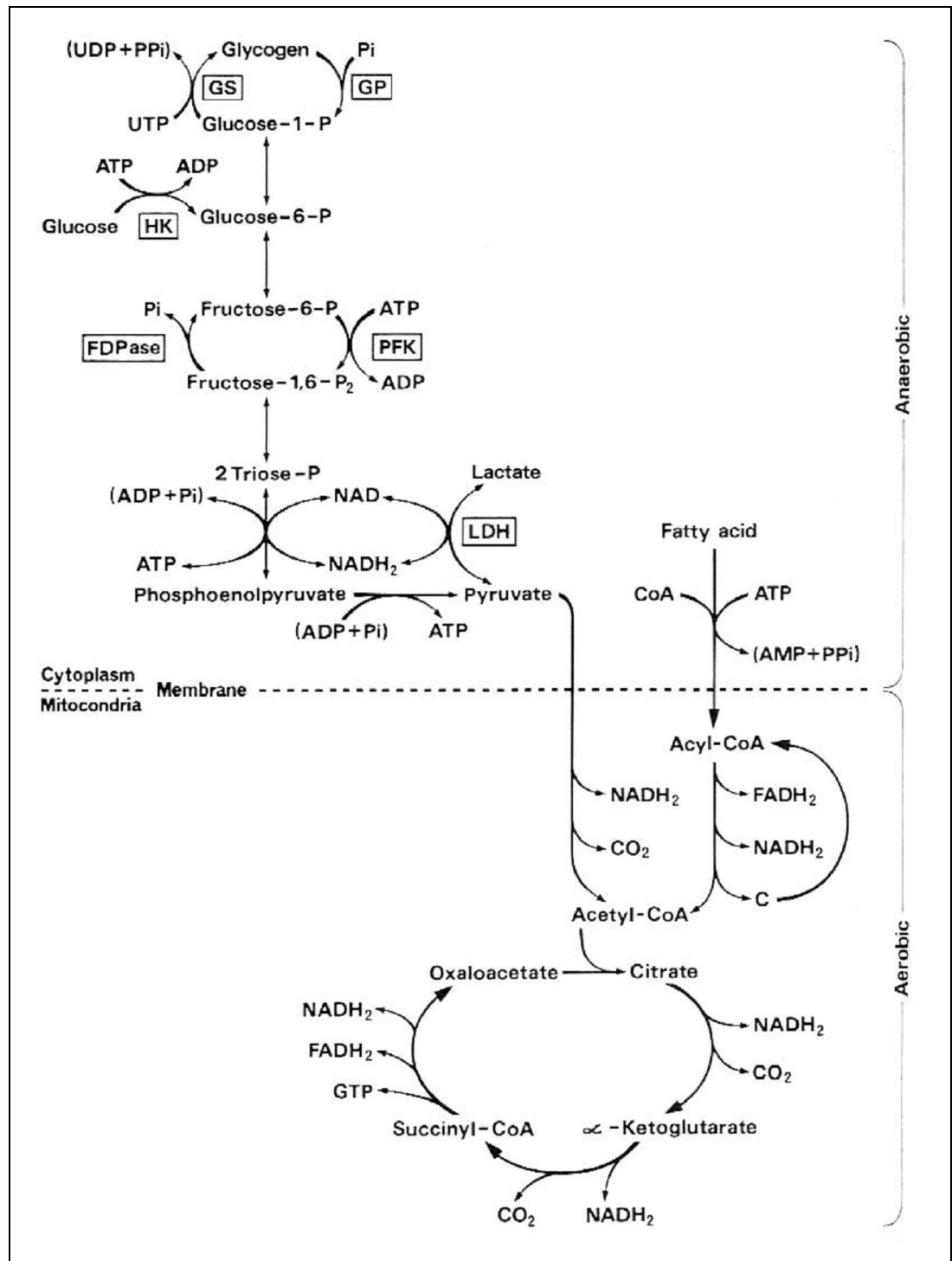

Figura 2: Glicólise, oxidação dos ácidos graxos e ciclo do ácido tricarboxílico na célula muscular.

Fonte: (HODGSON; ROSE, 1994).

Os cavalos possuem uma capacidade limitada de produzir energia por via aeróbica devido à disponibilidade do oxigênio no trabalho muscular (EVANS, 2000). Com a continuidade do exercício, as células passam a utilizar mais a glicose (exercício moderado) e, devido a deficiência no aporte de oxigênio às células (exercício intenso) ocorre um desvio metabólico, onde se inicia a formação de ATP pelos processos glicolíticos (anaeróbicos) com formação de ácido lático (SILVA, 2005). Este é um momento importante durante o exercício, onde caracterizamos o limiar anaeróbico, que é momento no qual o metabolismo aeróbico já não é suficiente para produzir ATP e necessita do metabolismo anaeróbico, havendo a formação de ácido lático que por sua vez desencadeará uma acidose metabólica (SILVA, 2005). 
O ácido lático (H-lactato) rapidamente se difunde para o plasma onde é tamponado pelo bicarbonato de sódio $\left(\mathrm{NaHCO}_{3}\right)$ resultando na formação de lactato de sódio (Na- lactato, um sal) e de ácido carbônico $\left(\mathrm{H}_{2} \mathrm{CO}_{3}\right)$, que se dissocia em água e $\mathrm{CO}_{2}$ (denominado de $\mathrm{CO}_{2}$ metabólico) (H-lactato $+\mathrm{NaHCO}_{3} \longrightarrow \mathrm{Na}$ - lactato + $\mathrm{H}_{2} \mathrm{CO}_{3} \longrightarrow \mathrm{H}_{2} \mathrm{O}+\mathrm{CO}_{2}$ ) (SILVA, 2005). Com o aumento do ácido lático plasmático (lactacidemia) e da $\mathrm{pCO}_{2}$ (hipercapnia) ocorre uma hiperventilação para eliminar o excesso de $\mathrm{CO}_{2}$ produzido e compensar a acidose metabólica (SILVA, 2005).

Durante o exercício ocorre uma série de eventos tanto fisiológicos quanto metabólicos, incluindo entre estes o aumento da temperatura central e muscular e estresse oxidativo (MARTINOD et al, 2007). Essas alterações fisiológicas ocorrem durante o exercício na tentativa de restabelecer os parâmetros do animal. Alguns autores como GRAMKOW; FERRAZ (2007) citaram adaptações como o aumento da taxa metabólica; taquicardia e elevação do débito cardíaco; taquipnéia e aumento da negatividade da pressão intratorácica; elevação da pressão arterial média (até 120 $\mathrm{mmHg}$ ); vasodilatação na musculatura ativa (músculo-esquelética); hiperventilação; abertura de capilares e alvéolos pulmonares; aumento da viscosidade sanguínea; aumento da resistência ao fluxo sanguíneo em diversos órgãos (pulmões); depleção de glicogênio intramuscular com acúmulo de lactato em músculos esqueléticos; vasodilatação coronária para levar oxigênio para a contração miocárdica; vasoconstrição esplênica para redistribuição de sangue na circulação periférica e duplicação do hematócrito a $\mathrm{VO}_{2} \mathrm{max}$; aumento do fluxo sanguíneo para pele com dilatação dos vasos, a fim de facilitar a perda de calor; aumento do movimento muscular para melhor bombeamento do sangue de retorno; $\mathrm{VO}_{2} \max$ limitado pelo fornecimento de $\mathrm{O}_{2}$ a mitocôndria, e não pela capacidade oxidativa intrínseca da organela. Thomassian et al. (2007) citam o aumento dos níveis séricos de alanina aminotransferase (AST), creatina quinase (CK) e lactato desidrogenase (LDH) imediatamente após o exercício, retornando aos níveis basais 30 minutos após o exercício.

Durante exercício mais intenso a inspiração ocorre durante a fase de vôo da passada e pelo deslocamento para cima do pêndulo crânio-cervical, ou seja, elevação da cabeça e do pescoço, e pelo deslocamento das vísceras caudalmente, devido à inércia do movimento visceral (HODGSON; ROSE, 1994), sendo que neste momento a área de maior energia cinética ocorre na laringe (RAKESH et al, 2008). A expiração se inicia na fase de apoio da passada, quando ocorre o abaixamento da cabeça e do pescoço e o 
deslocamento das vísceras cranialmente (HODGSON; ROSE, 1994), durante este período a maior energia cinética ocorre na nasofaringe (RAKESH et al, 2008).

No início do exercício a taxa de produção de calor no músculo é maior que a taxa de dissipação de calor, o que resulta em rápida elevação da temperatura muscular. Esta pode aumentar até $1^{\circ} \mathrm{C}$ por minuto no início de um exercício extenuante. Temperaturas musculares de $45^{\circ} \mathrm{C}$ já foram reportadas em cavalos em exercício (HODGSON; ROSE, 1994).

O aumento da temperatura muscular resulta na melhoria da performance muscular, pois facilita a liberação de oxigênio para os glóbulos vermelhos. Este aumento ainda estimula termorreceptores localizados centralmente, provocando um aumento do fluxo sanguíneo para a pele, e se inicia a sudação. $\mathrm{O}$ aumento do fluxo sanguíneo da pele transfere o calor para fora dela. A temperatura da pele é inicialmente mais baixa que a temperatura central. O calor é obtido como um subproduto do trabalho muscular e é transferido da pele para o ambiente por convecção, condução, radiação e evaporação do suor e também pela via respiratória, como pode ser visto na figura 3 (HODGSON; ROSE, 1994).

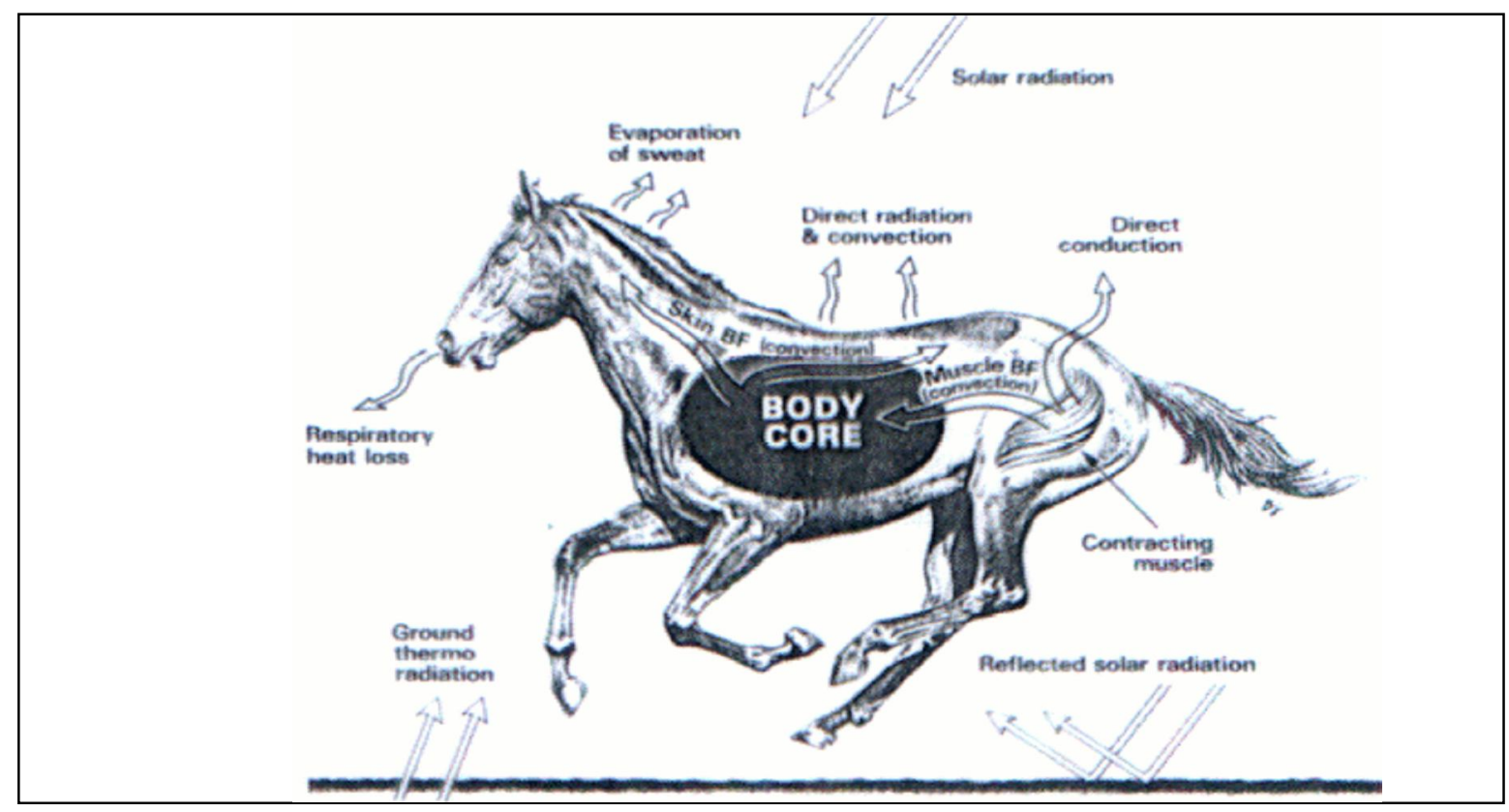

Figura 3: Mecanismo de transferência de calor no corpo de um cavalo. Fonte: (HODGSON; ROSE, 1994)

O lactato é produto do metabolismo muscular nos exercícios e seu auresultante da limitação da disponibilidade de oxigênio para oxidação do piruvato na mitocôndria (THOMASSIAN, 2005). Morgado; Galzerano (2006) descrevem trecho citado por 
Lehninger et al (1995) concluindo que a produção excessiva de lactato e seu acúmulo levam a queda do pH, devido o aumento das concentrações de íons $\mathrm{H}+$, que é gerado pela dissociação do ácido lático em lactato e H+ (SALES et al, 2005).

O aumento de lactato plasmático leva a uma hiperventilação na tentativa de eliminar o excesso de $\mathrm{CO}_{2}$ produzido, compensando a acidose metabólica (BALDISSERA, 1997). Evans (2000) afirma que o acúmulo de lactato nas células musculares durante o exercício contribui para o desenvolvimento da fadiga.

No exercício de intensidade progressiva, as concentrações de lactato aumentam em média a partir de 1 mmol/L (GRAMKOW; FERRAZ, 2007), Evans (2000) ressalta que a concentração de lactato sanguíneo de equinos em repouso é de aproximadamente 0,5 mmol/L, sendo que o exercício pode aumentar para 20 a $30 \mathrm{mmol} / \mathrm{L}$ ou mais. A intensidade de esforço físico onde as concentrações de lactato aumentam é denominada limiar de lactato (GRAMKOW; FERRAZ, 2007), e é representado por $4 \mathrm{mmol} / \mathrm{L}$ (FERRAZ, 2007; FERRAZ et al, 2008). Com a intensa produção de lactato ocorre diminuição do $\mathrm{pH}$, podendo limitar a capacidade do trabalho por interferir na atividade enzimática muscular (THOMASSIAN, 2005).

A fadiga é um importante fator que afeta a performance no exercício (PICCIONE et al, 2005). Lewis (2000), caracteriza a fadiga pós exercício por um equino que vários dias após o esforço prolongado permanece deprimido e letárgico, Evans (2000) acrescenta que a fadiga é uma diminuição na capacidade de continuar no exercício, manifestando no cavalo uma queda na performance que está associada ao declínio na concentração de ATP nas células musculares com consequente acúmulo de ADP e Pi, concluindo que a fadiga ocorre pela combinação dos efeitos de exaustão do suprimento de energia, hipertermia e desidratação. Hodgson; Rose (1994), descrevem a fadiga como uma complexa cadeia de eventos, onde possui participação central e periférica. A fadiga central desenvolve-se no sistema nervoso central e envolve a serotonina cerebral (5-HT). O sistema seratoninérgico é associado com várias funções cerebrais que pode atuar positiva ou negativamente durante o exercício. Consequentemente a síntese e o metabolismo de 5-HT no cérebro aumentam em resposta ao exercício, além de que a concentração de serotonina no cérebro é associada a marcadores da fadiga central como, redução de movimentos, letargia, cansaço e incoordenação motora (PICCIONE et al, 2005). Sendo esta o resultado de um déficit corporal de energia, água ou eletrólitos (Lewis, 2000), com queda na performance ocorrendo como um mecanismo de 
defesa para evitar danos irreversíveis devido ao excesso de esforço (PICCIONE et al, 2005).

\section{CONCLUSÃO}

A partir desta revisão, foi possível concluir a importância clínica da fisiologia do exercício em cavalos atletas, considerando o treinamento e a suplementação, fatores de grande importância para a performance destes animais, para uma melhor recuperação após o esforço e para evitar a fadiga, sendo que para cada modalidade exercida pelo animal existe um suplemento que é mais efetivo, como por exemplo, o uso da creatina nos exercícios de curta duração e alta intensidade e a utilização de suplementos contendo glicose e carboidratos nos exercícios de longa duração e baixa intensidade. Vale ainda ressaltar a importância de suplementos eletrolíticos no pós esforço para que o animal permaneça ingerindo água nesse momento, considerando que cavalos que passaram por esforços intensos ou fatigados normalmente não ingerem ou diminuem a ingestão de água.

\section{REFERÊNCIAS}

BALDISSERA, V. Fisiologia do exercício para equinos. Caderno Técnico da Escola de Veterinária da UFMG. n. 19. 1997. 39- 48 p.

EVANS, D.L. Training and fitness in athletic horses. Sydney: University of Sydney. Department of Animal Science, 2000.

FERRAZ, G.C. Fisiologia do exercício e performance equina. In SEMANA ACADÊMICA DE ZOOTECNIA DA UFPR. Curitiba, 2007. Disponível em:

<http://www.gege.agrarias.ufpr.br/Anais/Fisiologia.pdf>. Acesso em: 14 nov. 2008.

FERRAZ, G.C. et al. Blood lactate threshold reflects glucose responses in horses submitted to incremental exercise test. Arquivo Brasileiro de Medicina Veterinária e Zootecnia. Belo Horizonte, v. 60, n. 1, 2008.

GRAMKOW, H.L.; FERRAZ, G.C. Fisiologia do exercício em equinos. Vet. Polo Clínica Veterinária, 2007. 
GUERRA, P.; MEDEIROS, S.A.F. Estudo mostra que mercado equino gera R\$ 7,3 bilhões por ano. Confederação da Agricultura e Pecuária do Brasil. (s/l), 2006. Disponível em: <http://www.cna.org.br/site/noticia.php?n=13894>. Acesso em: 08 set. 2008.

GUIMARÃES, J.L.; ADELL, E.A.A. Estrutura e bioquímica do músculo. Unicamp, 1995. 34 p. (Apostila do Laboratório de Carnes)

HODGSON, D.R.; ROSE, R.J. The athletic horse: principles and practice of equine sports Medicine. Philadelphia: Saunders, 1994. 497 p.

LACERDA, J.C.N. Respostas orgânicas ao exercício físico. In: SIMPÓSIO DE NUTRIÇÃO DE EQUINOS, 1. Campinas, 2004.

LEHNINGER, A.L.; NELSON, D.L.; COX, M.M. Princípios de bioquímica. São Paulo: Sarvier, 2000. $552-557$ p.

LEWIS, L. D. Nutrição clínica equina: alimentação e cuidados. São Paulo: Roca, 2000. p. $329-332$.

MARTINOD, S.R. et al. Release of heat shock protein Hsp 72 after exercise and supplementation with na opuntia fícus indica extract TEX-OE. In: ANNUAL CONVENTION OF THE AMERICAN ASSOCIATION OF EQUINE PRACTITIONERS, 53. Proceedings... Orlando, Florida, USA, 1-5 Dec., 2007. p.72-76.

MORGADO, E.; GALZERANO, L. Utilização de óleo em dietas para equinos. Revista Eletrônica de Veterinária. v. 2, n. 10, 2006. Disponível em:

<http://www.veterinaria.org/revistas/redvet/n101006.html>. Acesso em: 21 out. 2008.

PICCIONE, G. et al. Central fatigue and nycthemeral change of serum tryptophan and serotonin in the athletic horse. Journal of Circadian Rhythms, Italia, 2005.

RAKESH, V. et al. Development of equine upper airway fluid mechanics model for thoroughbred racehorses. Equine Veterinary Journal. v. 40, n.3, p. 272-279, 2008.

SALES, R.P. et al. Efeitos da suplementação aguda de aspartato de arginina na fadiga muscular em voluntários treinados. Revista Brasileira de Medicina do Esporte. Niterói, v. 11, n. 6, 2005.

SILVA, L.Q.P. Fisiologia do exercício no cavalo atleta. 2005. 50 f. Monografia. Faculdade de Medicina Veterinária e Zootecnia, Universidade Estadual Paulista. Jaboticabal.

THOMASSIAN, A. Enfermidades dos cavalos. São Paulo: Varela, 2005. p. 81 - 94.

THOMASSIAN, A. et al. Serum activities of aspartate aminotransferase, creatina kinase and lactate dehydrogenase in arabian horses submitted to standard incremental exercise test. Brazilian Journal of Veterinary Research and Animal Science. v.44, n. 3, p. $183-190,2007$. 
